\title{
Orthographic Processing of Polysyllabic Words by Native and Nonnative English Speakers
}

\author{
Marcus Taft \\ University of New South Wales, Sydney, New South Wales, Australia
}

Published online January 22, 2002

\begin{abstract}
How polysyllabic English words are analyzed in silent reading was examined in three experiments by comparing lexical decision responses to words physically split on the screen. The gap was compatible either with the Maximal Onset Principle or the Maximal Coda Principle. The former corresponds to the spoken syllable (e.g., ca det), except when the word has a stressed short first vowel (e.g., ra dish), while the reverse is true for the latter (giving cad et and $\mathrm{rad}$ ish). Native English speakers demonstrated a general preference for the Max Coda analysis and a correlation with reading ability when such an analysis did not correspond with the spoken syllable. Native Japanese speakers, on the other hand, showed a Max Onset preference regardless of the type of word, while native Mandarin Chinese speakers showed no preference at all. It is concluded that a maximization of the coda is the optimal representation of polysyllabic words in English and that poorer native readers are more influenced by phonology than are better readers. The way that nonnative readers mentally represent polysyllabic English words is affected by the way such words are structured in their native language, which may not lead to optimal English processing. ๑) 2002 Elsevier Science (USA)
\end{abstract}

Key Words: bilingual reading; Chinese/English bilinguals; Japanese/English bilinguals; lexical processing; orthographic processing; reading ability; reading strategies; syllables; word recognition.

There is more to the internal orthographic structure of a visually presented word than just its morphology. While it is the case that a word like gardeners can be broken down into its morphemes garden, er, and $s$, it is also possible for its stem garden to be analyzed further into syllables. There is then the question of what those syllables are. The spoken syllabic structure appears to place the syllable boundary between the $r$ and the $d$, but this may not necessarily correspond to the structure relevant to orthographic processing. For example, a division between the $d$ and the $e$ is a possibility.

The linguistic definition of the spoken syllable boundary draws upon the principle of Maximal Onset (see, for example, Spencer, 1996). According to this principle, syllabification leads to the greatest possible number of onsets within a word. An "onset" refers to the consonants that immediately precede the vowel within any syllable, so that dividing garden between the $r$ and the $d$ produces two onsets (i.e., the $g$ of gar and the $d$ of den), whereas a gard-en division produces only one (i.e.,

The research reported in this article was supported by a grant to the author from the Australian Research Council. The assistance of Louisa Carroll, Tomoko Sugiura, and Xiaoping Zhu in conducting the experiments in English, Japanese, and Chinese respectively is gratefully acknowledged.

Address correspondence and reprint requests to Marcus Taft, School of Psychology, University of NSW, Sydney NSW 2052, Australia. E-mail: M.Taft@unsw.edu.au. 
the $g$ of gard). In the latter example, the $d$ is no longer an onset, but rather is part of the coda of the first syllable, where a "coda" is the consonant or consonant cluster that immediately follows the vowel.

In most languages, the use of the Maximal Onset Principle is uncontroversial when it comes to pronunciation. For example, Spanish pronunciation clearly places a medial consonant in the onset position of the following syllable rather than in the coda position of the preceding one (giving, for example, mu-cha-cho rather than much$a c h-o$ ). In Japanese, the Maximal Onset Principle is so clear that it is explicitly formalized within its orthographic system. The kana scripts (both katakana and hirigana) provide different characters for consonant-vowel (CV) structures (e.g., mi, mo, and no are each represented by a very different character), but never provide any character for vowel-consonant (VC) combinations. Indeed, the only consonant that occurs in a coda position within a Japanese syllable (i.e., $n$ ) is treated as a separate unit (mora) with its own kana character. Thus a CVC syllable (e.g., min) is written in kana using two characters (the one for $m i$ and the one for $n$ ).

In English, there are also clear-cut cases where the Maximal Onset Principle applies. The syllable boundary following an unstressed syllable clearly places the medial consonant in the following syllable, thus maximizing the onset. For example, cadet is pronounced with a boundary between the $a$ and the $d$. When a consonant follows a long vowel, it also becomes the onset of the subsequent syllable (with spider, for example, being pronounced with a division between spi and der). In addition, medial consonant clusters (like the $c t$ of doctor) are pronounced with a division between the consonants, hence allowing each syllable to have an onset (doc and tor).

When it comes to the remaining type of polysyllabic English word, however, it is apparent that the Maximal Onset Principle is not so straightforward. These are words with a short stressed vowel followed by a single consonant, like melon, where a division immediately after the vowel would isolate a syllable that ends in a final short vowel, which is unacceptable in English. That is, if the first syllable of melon were taken to be $m e$, that syllable would end in $/ \varepsilon /$, a sound that is never found in the final position of a monosyllabic word (as opposed to the long vowel /i:/, as in the word $m e$ ). The Maximal Onset Principle can be maintained, however, by suggesting that while the medial consonant is required as a coda in the first syllable, it also acts as the onset of the second syllable (e.g., Kahn, 1976/1980). That is, the consonant can be "ambisyllabic.",

While the Maximal Onset Principle may provide a good description of the spoken syllabic structure of words, there is reason to believe that it is not an optimal approach to the orthographic processing required in reading. Even in spoken word recognition, there is little evidence that native English speakers are sensitive to syllable structure (e.g., Bradley, Sánchez-Casas, \& García-Albea, 1993; Cutler, Mehler, Norris, \& Segui, 1986), so the idea that visual word recognition makes use of syllabically defined units is problematical, though such a proposal has been put forward (e.g., Adams, 1990; Spoehr \& Smith, 1973). Moreover, there is an inherent incompatibility between the idea that morphological structure is represented in the lexical processing system in tandem with a structure based on the spoken syllable. For example, the syllable boundary of heating and heater follows the ea, while heats has no syllable boundary at all, being monosyllabic in pronunciation. Of course, the morphological structure places the boundary after the $t$ in each case (because the stem is heat) and, therefore, such words cannot be activated in lexical memory on the basis of both their morphological and syllabic structure at the same time.

It was largely for this reason that Taft (1979) put forward the idea that visually presented polysyllabic words are structured in lexical memory in terms of subunits that are defined on both an orthographic and morphological basis. This was termed 
the Basic Orthographic Syllabic Structure (BOSS), which assumed that the first subunit of the stem of a word is most important in its recognition. The amount of information contained in that subunit is optimized by drawing a structural boundary after all of the consonants that follow the first vowel of the stem morpheme. For example, the BOSS of cadet is cad, the BOSS of spider is spid, and the BOSS of doctor is doct. Other examples are the mel of melon and the heat of heater, heats, and reheat (because heat is the stem morpheme). In addition, the BOSS of kidney will be kid rather than kidn because $d n$ is not a legal coda (as evidenced by the fact that no word ends in $d n$ ).

It can be seen, then, that the BOSS does not correspond to the spoken syllable. Indeed it totally violates the Maximal Onset Principle, except in the case of short stressed vowels (as in melon) where it does at least coincide with the first spoken syllable (e.g., $\mathrm{mel}$ ). Instead of maximizing the onset of the second syllable, the orthographic syllabic structure actually maximizes the coda of the first syllable. That is, the $d$ of cadet becomes the coda of the first subunit ( $c a d)$ rather than the onset of the second subunit; and the $t$ of doctor joins with the $c$ to give the first subunit a complex coda, thus depriving the second subunit of any onset. So, the BOSS reflects an application of what can be called the Maximal Coda Principle.

The evidence that Taft presented to support the BOSS notion came primarily from experiments where polysyllabic words were presented for lexical decision with a physical division made within the word (Taft, 1979, 1987). The physical division was created in a number of ways, including the use of a space between subunits, a change of case, and a temporal delay between the presentation of subunits. It was found in these studies that lexical decision times were faster when the division was congruent with the BOSS (e.g., cad et) than when it was congruent with the spoken syllable (e.g., ca det). In addition, adding one letter to the BOSS (e.g., cade) did not lead to faster response times relative to the BOSS (Taft, 1987), even though this BOSS +1 fragment provides more graphemic information about the word of which it is a part.

Although several other studies have failed to find any support for the importance of the BOSS (e.g., Jordan, 1986; Lima \& Pollatsek, 1983), there has recently emerged a possible explanation for this. It happened that many of the participants used in Taft's studies were drawn from the higher level undergraduate and graduate programs, rather than from the more standard first-year undergraduate pool, and it is therefore possible that the data came from a sample of rather better readers than in other studies. If it is the case that a BOSS analysis is the optimal approach to visual word recognition, then one might only expect that the use of the BOSS will be observed for better readers (see also Leong \& Parkinson, 1992, for such a suggestion). Furthermore, there is evidence to suggest that poorer adult readers are more dependent on phonological processing when reading silently (e.g., Jared, Levy, \& Rayner, 1999; Lewellen, Goldinger, Pisoni, \& Greene, 1993), from which one might conclude that such readers might find it easier to read a word divided according to its syllable boundary than according to its BOSS. Therefore, the inclusion in an experiment of a large number of relatively poor readers could potentially counteract any BOSS preference shown by the better readers.

In support of this possibility, Taft (2001) has recently found in several experiments a significant correlation between reading ability (as measured in terms of an objective comprehension test) and BOSS preference (e.g., response times to cad et relative to response times to $\mathrm{ca}$ det). Moreover, in a separate examination of relatively good and relatively poor adult readers, a significant BOSS preference was found for the former and a syllable preference for the latter. So, although no effect of boundary position was observed in any of the experiments averaged across all of the partici- 
pants, it is apparent that this was because readers at each end of the proficiency scale were showing a different preference pattern.

There are several important implications arising from such findings. First, the claim that phonological processing is of central importance in silent reading (e.g., Frost, 1998; Lukatela, Lukatela, \& Turvey, 1993; Van Orden, 1987) may be true in English, but only for poorer readers (cf. Jared et al., 1999; Lewellen et al., 1993). Second, proficient reading of English involves the optimization of the initial subunit of a polysyllabic word, and this is achieved by maximizing the coda. Third, if maximization of the coda is important for proficient English reading, this could prove to be a problem for nonnative readers if they are simply transferring orthographic processing strategies from a native language for which the VC structure (vowel + coda) has no status.

The first experiment to be reported in this article aims to replicate and extend the findings that support the importance of the BOSS in proficient English reading, while the subsequent experiments examine whether inappropriate transfer does occur in nonnative reading of English.

\section{EXPERIMENT 1: NATIVE ENGLISH SPEAKERS}

When poorer readers demonstrate faster lexical decision responses to syllabledivided words (e.g., ra dio) over BOSS-divided words (e.g., rad io), we do not know if they are really basing their analysis on phonological considerations (i.e., syllable structure) or if they are merely trying to get the recognition process underway on the basis of minimal orthographic information (i.e., the initial CV unit). That is, we can ask whether it is important that the ra of radio is its first syllable as opposed to it merely being the first unit isolated via the Maximal Onset Principle. These two possibilities can be discriminated by examining words that have a short stressed first vowel with a single following consonant (e.g., melon and radish).

As pointed out above, the first syllable of such words maximizes the coda in the same way that the BOSS does (even if the medial consonant might become the onset of the second syllable as well). So, the first syllable of radish would be rad and, therefore, if a reader is analyzing this word according to its spoken syllable structure, responses to rad ish should be faster than to $\mathrm{ra}$ dish, just as they would be if the reader is using a BOSS analysis. This means that all readers, both good and poor, should show a preference for a maximal coda ("Max Coda") analysis over a maximal onset ("Max Onset') analysis when the first vowel is short and stressed. However, for all other types of polysyllabic word (e.g., those with long first vowels, like radio, or a medial consonant cluster, like doctor), the preference for Max Coda over Max Onset should only be observed for better readers, as previously shown (Taft, 2001). Thus, the correlation between reading ability and Max Coda preference should emerge only when the word does not have a short, stressed first vowel.

\section{Method}

Materials and procedure. Two sets of 40 words were used as experimental items. In the first set (the "Short Vowel" condition), all of the words had a stressed short first vowel followed by a single consonant (e.g., radish, memory, and balance). The mean word frequency was $43.0 / \mathrm{million}$. The second set mostly comprised words with a long first vowel (e.g., radio and silence), but also included some with a medial consonant cluster (e.g., doctor and harvest). This set will be called the "Long Vowel", condition and had a mean frequency of $36.7 /$ million. The items are presented in the Appendix.

One group of participants saw half of the experimental items with a gap of two spaces at the boundary that marked the Max Onset analysis (e.g., doc tor and $r a$ dish) and the other half with the gap at the Max Coda boundary (e.g., rad io and mem ory), while a second group saw the items in the opposite 
condition (i.e., ra dio and me mory; doct or and rad ish). The 80 experimental items were presented in random order along with 60 nonwords that were similarly structured (e.g., brolance, dacus, sarphor, and beldine) and that were divided either in terms of a Max Onset analysis (e.g., bro lance) or a Max Coda analysis (e.g., beld ine). Both groups saw the same set of nonwords. Ten practice items preceded these words and nonwords.

Participants were given instructions, both orally and in writing, that they would see a letter-string split into two parts on the screen and that they were to decide as quickly but as accurately as possible whether that letter-string formed a real word when the two parts were combined. Responses were made by pressing a "yes" or "no" button. Each item was presented on a desktop monitor in lowercase letters for $500 \mathrm{~ms}$ with an intertrial interval of $1 \mathrm{~s}$ after the response.

After completing the experiment, the participants were given the same paper-and-pencil reading comprehension test that was used in the previous Taft studies (2001). This test comprised a series of short passages each followed by three to seven multiple choice questions. The test was based upon the Cooperative Reading Comprehension Test developed by the Australian Council of Educational Research and resembled the comprehension component of the Nelson-Denny Reading Test (Brown, Fishco, \& Hanna, 1993). The 57 multiple-choice questions (coming from a total of 12 passages) each had five alternative answers to choose from. A time limit of 15 min was tightly adhered to and participants were told that they were not expected to complete the whole test.

Participants. There were 52 participants (26 in each group) recruited largely from the pool of firstyear psychology students, but also from higher levels, including graduate students. They were all monolingual English speakers.

\section{Results and Discussion}

Table 1 presents the mean RTs and error rates for Experiment 1.

For the Short Vowel items (e.g., radish), where both the BOSS and syllable coincide with the maximal coda analysis, there was a significant advantage for the Max Coda ( $r a d$ ish) over the Max Onset ( $r a$ dish) on both RT and error rates, $F 1(1,50)=4.78, p<.05 ; F 2(1,39)=23.07, p<.001$, and $F 1(1,50)=5.34$, $p<.05 ; F 2(1,39)=6.13, p<.05$ respectively.

The Long Vowel items (e.g., radio) were equivalent to those used in Taft's recent experiments where no overall BOSS (i.e., Max Coda) preference was observed. In the present experiment, however, there was a strong indication of a Max Coda preference, with the item analysis of RT reaching significance, $F 1(1,50)=1.70, p>.05$; $F 2(1,39)=7.87, p<.01$ for RT, as well as the participant and item analyses of the error rates, $F 1(1,30)=6.18, p<.05 ; F 2(1,39)=5.30, p<.05$.

No overall Max Coda (BOSS) effect for Long Vowel words was observed by Taft in his recent studies, nor by Lima and Pollatsek (1983), so why might there be one here? The explanation one can give is the same as that used to explain why Taft's earlier studies $(1979,1987)$ might have also shown such an effect, namely in terms

\section{TABLE 1}

Lexical Decision Times (in Milliseconds) and Error Rates (in Parentheses) for the Native English Speakers of Experiment 1 to Words Presented with a Physical Gap That Coincided with Their Maximal Coda Analysis (Max Coda) or Their Maximal Onset Analysis (Max Onset)

\begin{tabular}{lccc}
\hline & Max Coda & Max Onset & Difference \\
\hline Long vowel & rad io & ra dio & \\
& 595 & 610 & +15 \\
Short vowel & $(1.8 \%)$ & $(3.5 \%)$ & $(+1.7 \%)$ \\
& rad ish & ra dish & \\
& 577 & 603 & +26 \\
& $(2.2 \%)$ & $(4.2 \%)$ & $(+2.0 \%)$ \\
\hline
\end{tabular}


of there being a preponderance of better readers among the participants. It seems that in the present experiment the reading proficiency of the participants happened by chance to be biased toward the upper end of the scale. In Taft's previous experiments looking at reading ability, "good" reading (i.e., approximately the top 25\%) was taken to be more than 22 answers correct in the reading comprehension test, while "poor" reading (i.e., approximately the bottom $25 \%$ ) was taken to be less than 13 answers correct. The average score was 18.1. While the average score in the reading comprehension test for the participants in the current experiment was somewhat higher than this (mean number correct $=20.1$ ), the difference is most obvious when looking at the proportion of good and poor readers in the study. In the current experiment, $37.5 \%$ of participants scored in the good reading range, with only $15.6 \%$ in the poor reading range. Thus, the fact that there happened to be a preponderance of good readers in this experiment could well have contributed to the greater indication of an overall BOSS (Max Coda) preference.

Of course, such a conclusion would only make sense if Max Coda preference for Long Vowel words were found to correlate with reading ability, so this was examined following the same procedure as in Taft's earlier correlational experiments. In particular, the reading comprehension measure was the total number of multiple-choice questions correctly answered, though the number completed was also examined in case speed was more important than accuracy.

The Max Coda preference measure was determined by subtracting RTs to the Max Coda condition from those to the Max Onset condition. In fact, it was found in the earlier studies that this difference score correlated less highly with reading performance than did a ratio of this difference score to the participant's overall RT and, therefore, such a ratio difference score was used here. In this way, the 20-ms difference between means of, say, 520 and $500 \mathrm{~ms}$ have a greater impact than that between means of 1520 and $1500 \mathrm{~ms}$. Finally, these ratio difference scores were converted into $z$ scores for each of the two participant groups because each group received a different set of items under the two conditions. Therefore, the correlation of lexical decision responses with reading performance was conducted on the standardized form of the difference for each participant between their mean RT to each condition relative to their overall RT.

As predicted, there was a significant correlation for the Long Vowel items between reading ability and the preference for Max Coda over Max Onset $(r=+0.273, p<$ .05 for Total Correct, and $r=+0.248, p<.1$ for Total Completed). In addition, there was no such correlation for the Short Vowel items $(r=+0.129, p>.1$ for Total Correct, and $r=+0.079, p>.1$ for Total Completed), indicating that even poorer readers prefer the Max Coda over the Max Onset division when it is congruent with the syllable boundary.

These results suggest that the difference between good and poor readers in terms of their preference for a maximal coda analysis only arises when such an analysis conflicts with the phonological structure of the word. A maximal coda division appears to be compatible with the way better readers mentally represent any polysyllabic word. Poorer readers, however, appear to prefer an orthographic division that is compatible with the pronunciation of the word regardless of whether it maximizes the coda or the onset.

This compatibility in pronunciation has been described here in terms of the spoken syllable structure, but it is also possible that it has more to do with the pronunciation of the vowel. For Long Vowel words, the Max Onset division often produces an initial unit that is pronounced appropriately, while the Max Coda division does not. For example, the $o$ of mo is pronounced in the same way as it is in moment, but the $o$ of mom is not. For Short Vowel items, it is the Max Coda division that provides 
the appropriate pronunciation (e.g., the $o$ of mod in modern as opposed to the $o$ of $m o$ ). So, it is possible that poorer readers simply prefer an analysis that is compatible with the pronunciation of the word in terms of its vowel. In fact, not all Long Vowel items have a Max Onset vowel that is more congruent with the word's pronunciation than is its Max Coda vowel. In particular, the vowel of words with a medial consonant cluster (e.g., doctor) is the same whether it be in the BOSS (doct) or in the initial syllable $(d o c)$. So, whether it is the vowel or the syllable structure that is most relevant to poorer readers could be tested by comparing Long Vowel items like moment with those like doctor. This has yet to be done.

\section{EXPERIMENT 2: NATIVE JAPANESE SPEAKERS}

Having gained an indication of the pattern of native processing of polysyllabic words, the research now turns to nonnative processing. The first nonnative group to be examined is one for which the Maximal Coda Principle is likely to be the most alien, namely native Japanese speakers.

As pointed out above, the kana script used in Japanese captures onset-vowel combinations, but never vowel-coda combinations. Indeed, Otake, Hatano, Cutler, and Mehler (1993) and Inagaki, Hatano, and Otake (2000) have clearly demonstrated that adult Japanese speakers have enormous difficulty combining a coda with its preceding vowel when processing spoken words. For example, only about $1 \%$ of the adult Japanese speakers tested by Inagaki et al. (2000) were able to detect the spoken syllable min in the spoken word minoji, although almost all could detect it in minji. That is, the target syllable was undetectable when its coda (i.e., $n$ ) formed an onset within the word in which it occurred (i.e., in minoji, but not in minji). Inagaki et al. (2000) proposed that this result arose from orthographic knowledge, namely from the fact that $n$ has no independent kana representation in minoji because it is subsumed within the single kana character used for the syllable no. Their evidence for this suggestion came from the fact that children with only a limited knowledge of kana had far less difficulty in detecting the min of minoji than did adults.

Given the overriding dominance of the Maximal Onset Principle in the Japanese phonological system as reinforced by the orthographic system, the question then arises whether Japanese/English bilinguals overwhelmingly apply this principle when reading English. Such a transfer of orthographic processing strategies to English would be evidenced by a preference for a Max Onset division over a Max Coda division, not only for Long Vowel words (e.g., ra dio recognized faster than rad io), but for Short Vowel words as well (e.g., ra dish preferred to rad ish). In other words, it would be expected that Japanese bilinguals would behave like poorer native English readers when reading "long vowel" polysyllabic English words, but not when reading "short vowel" polysyllabic words (where poorer English readers prefer the Max Coda analysis). This is because the Japanese preference should be for a CV structure regardless of its pronunciation.

\section{Method}

Materials and procedure. The materials presented to the native Japanese speakers were the same as those used in Experiment 1. In fact, these words had been designed with the Japanese participants in mind because they were all judged by a native Japanese speaker to be within the vocabulary of the population of bilinguals from which the sample of participants was drawn. Furthermore, half of the Long Vowel and half of the Short Vowel items could actually be found in Japanese as words borrowed from English (e.g., radio and balance). The words that exist in Japanese were matched on frequency, item by item, with the words not used in Japanese. Words borrowed from another language are written in Japanese using the katakana script, and it is possible that a Japanese preference for the Max Onset 
analysis in English only holds for words whose orthography is already represented in lexical memory in a form that obviates a Max Coda analysis, namely a katakana representation of the word borrowed from English.

The procedure was also the same as in Experiment 1 except that a laptop computer was used in presenting the materials to the participants, who were each tested in a location that was convenient for them. Responses were made via the keyboard. Instructions were given verbally in Japanese, in addition to the English instructions that were displayed on the computer screen prior to the practice items.

Participants. Participants were 44 native Japanese speakers who had been speaking English for at least 4 years, living in Australia either temporarily or permanently. They were divided into two groups of 22 , but two participants in one of the groups were subsequently rejected from the experiment owing to error rates of over $50 \%$.

All participants were given a short questionnaire regarding their use of English, which provided the following statistics. The average age was $27.9(S D=7.11)$ and the average number of years being able to read English was $15.3(S D=8.44)$. The percentage of reading time spent reading English was selfestimated at an average of $46.4 \%(S D=21.42)$.

For practical expediency, only a random subset of 19 of the participants undertook the reading comprehension test. The average score from this sample was 7.79 correct $(S D=3.52)$ which was well within the "poor' native English range of less than 13 correct. Indeed, only two of the participants gained a score beyond this range, with scores of 13 and 15 .

\section{Results and Discussion}

Mean lexical decision times and error rates are given in Table 2, separated into words that are used in Japanese and those that are not.

In terms of RTs, a significant Max Onset preference was observed for both the Long Vowel and Short Vowel items, $F 1(1,40)=12.39, p<.01 ; F 2(1,39)=22.35$, $p<.001$ for the former; $F 1(1,40)=13.84, p<.001 ; F 2(1,39)=26.56, p<.001$ for the latter. There was no interaction between the size of the preference and the type of word, both $F 1$ and $F 2<1$. Also, it was clearly not the case that the Max Onset preference only held for words that existed as borrowed words in Japanese, with an overall 96-ms preference for such words compared to a $100 \mathrm{~ms}$ preference when the words did not exist in Japanese. Although the "Use in Japanese" factor

TABLE 2

Mean Lexical Decision Times (in Milliseconds) and Error Rates (in Parentheses) for the Japanese Participants in Experiment 2

\begin{tabular}{lccc}
\hline & Max Coda & Max Onset & Difference \\
\hline Long vowel & & & \\
Used in Japanese & rad io & ra dio & \\
& 1169 & 1101 & -68 \\
& $(7.7 \%)$ & $(7.7 \%)$ & $(0 \%)$ \\
Not used in Japanese & sil ence & si lence & \\
& 1271 & 1169 & -102 \\
& $(14.9 \%)$ & $(11.9 \%)$ & $(-3.0 \%)$ \\
Mean & 1220 & 1135 & -85 \\
& $(11.3 \%)$ & $(9.8 \%)$ & $(-1.5 \%)$ \\
Short vowel & & & \\
Used in Japanese & bal ance & ba lance & \\
& 1163 & 1039 & -124 \\
Not used in Japanese & $(7.1 \%)$ & $(5.7 \%)$ & $(-1.4 \%)$ \\
& rad ish & ra dish & \\
Mean & 1200 & 1103 & -97 \\
& $(8.3 \%)$ & $(4.1 \%)$ & $(-4.2 \%)$ \\
& 1182 & 1071 & -111 \\
& $(7.7 \%)$ & $(4.9 \%)$ & $(-2.8 \%)$ \\
\hline
\end{tabular}


did not interact with any other factor $(F<1$ in each case), there was a significant main effect of this variable. Responses to the words that were used in Japanese were significantly faster than responses to those that were not, $1118 \mathrm{~ms}$ versus $1186 \mathrm{~ms}$, $F 1(1,40)=23.23, p<.001 ; F 2(1,78)=7.13, p<.01$.

Such a main effect of Use in Japanese is perhaps unsurprising, but does hold some interest. For native English speakers, of course, the words that exist in Japanese are indistinguishable from those that do not, and indeed there was no sign at all of a difference in response times between the two types of word for the native speakers in Experiment 1, with exactly the same mean for each $(596 \mathrm{~ms})$.

Obviously, the words that are used in Japanese are more familiar to the Japanese speakers than the ones that are not used, but this means that familiarity of a word in one's L1 can affect the lexical representation of L2 words. What this suggests is that there is an overlap between language representation somewhere within bilingual lexical memory, not only at the level of meaning, but at a level that captures the combination of form and meaning. That is, the familiarity of the borrowed word when reading English cannot arise from its meaning alone nor from its form alone, but rather from the fact that the same form is used to mean the same thing. Such a conclusion is consistent with previous evidence indicating that there is an advantage in processing cognate words within the bilingual lexicon relative to noncognate words (e.g., Costa, Caramazza, \& Sebastian-Galles, 2000; de Groot \& Nas, 1991). Nonetheless, the results of Experiment 2 indicate that native Japanese speakers give a CV analysis to an English word (rather than a CVC or VC analysis) regardless of whether it has already been analyzed that way in Japanese.

The error analysis was not quite as straightforward as the RT analysis, with the only significant effect being a Max Onset preference for the Short Vowels, $F 1(1,40)=5.18, p<.05 ; F 2(1,39)=5.31, p<.05$. There would seem to be no way of explaining why the Max Onset preference should be significant for Short Vowels and not for Long Vowels (where the pronunciation of the latter is more congruent with the Max Onset analysis than the former), and indeed there was no significant interaction at all between preference and vowel length, both $F^{\prime}$ s $<1$.

We see, then, that nonnative English readers may adopt an orthographic analysis that is not ideal for effective English reading. Japanese constitutes the extreme example of a native language that would militate against the optimal English strategy. That is, the evidence points to a Maximal Coda strategy being the preferred analysis of better native English readers, whereas the internal structure of words in Japanese (as manifested in its orthographic system) supports a Maximal Onset strategy. The adoption of such a strategy by Japanese readers makes them different not only from better native English readers, but also from poorer native English readers who at least favor a Maximal Coda strategy when it is congruent with the spoken syllable structure.

\section{EXPERIMENT 3: NATIVE CHINESE SPEAKERS}

The final experiment examines another group of nonnative English speakers in an attempt to provide further information on the impact of one's L1 on L2 reading. In Mandarin Chinese, many words are composed of two or more syllables. Most syllables end in a long vowel (with the only syllable-final consonant being the nasal /n/ or $/ \mathrm{y} /$ ) and most syllables have a consonantal onset. Thus, the Maximal Onset principle clearly applies to the phonology of Mandarin Chinese.

However, for the vast majority of words in Chinese, a syllable is also a morpheme which is represented in the orthographic system as a single character. What this means 
is that, unlike English and Japanese readers, Chinese readers are unfamiliar with the notion that monomorphemic words might have an internal structure. For this reason, it is quite possible that native Chinese readers will be quite unsystematic in their approach to structuring the orthographic representation of English polysyllabic words. On the other hand, the relevance of the Maximal Onset Principle at the purely phonological level may lead to a Max Onset preference. Experiment 3 therefore tests Mandarin/English bilinguals to determine what their preference is in reading English.

\section{Method}

Materials and procedure. The materials and procedure were exactly the same as in the Japanese study except that oral instructions were given in Mandarin Chinese and the participants were tested in a laboratory setting using the same desktop computer that was used for the native English speakers of Experiment 1.

Participants. The participants were 36 native Mandarin speakers from the People's Republic of China, divided into two groups of 18. They had all been reading English for more than 4 years, and were residing in Australia either temporarily or permanently. From a questionnaire administered to the participants it was established that the average age was slightly higher than for the Japanese, being 33.1 $(S D=6.19)$, although the average number of years being able to read English was slightly lower, being $13.8(S D=5.80)$. On average, the Chinese participants were more inclined than the Japanese to spend time reading English, $70.6 \%$ of their reading time $(S D=27.07)$.

As in Experiment 2, only a random subset of the participants was given the reading comprehension test. The average number correct for this group of 18 participants was 7.39 correct $(S D=3.81)$, which was very similar to the Japanese performance level. As for the Japanese subgroup, only two participants gained a score beyond the "poor" range, again 1 with 13 correct and 1 with 15 .

\section{Results and Discussion}

Mean lexical decision times and error rates are given in Table 3.

In terms of RTs, the Chinese speakers showed no preference for one type of division over the other for either the Short or Long Vowel words, with all $F$ 's $<1$. While there was a trend toward a Max Coda preference on error rates, this proved to be nonsignificant both for the Long Vowels, $F 1(1,40)=1.66, p>.05 ; F 2(1,39)=$ $0.78, p>.05$, and for the Short Vowels, $F 1(1,40)=3.65, p>.05 ; F 2(1,39)=$ $2.70, p>.05$.

It is apparent that native Chinese speakers are unaffected by the way an English polysyllabic word is structured. This means either that they impose no special structure on English words or that some prefer a Max Onset analysis while others prefer a Max Coda analysis. What is apparent, though, is that the Chinese pattern of responding is different to that of other groups with similar reading proficiency. In particular, native Japanese speakers always prefer a Max Onset analysis, while poorer

\section{TABLE 3}

Mean Lexical Decision Times (in Milliseconds) and Error Rates (in Parentheses) for the Chinese Participants in Experiment 3

\begin{tabular}{lccc}
\hline & Max Coda & Max Onset & Difference \\
\hline Long vowel & rad io & ra dio & \\
& 740 & 741 & +1 \\
Short vowel & $(10.5 \%)$ & $(11.5 \%)$ & $(+1.0 \%)$ \\
& rad ish & ra dish & \\
& 740 & 741 & +1 \\
& $(15.2 \%)$ & $(18.3 \%)$ & $(+3.1 \%)$ \\
\hline
\end{tabular}


native English speakers appear to prefer a Max Coda analysis for Short Vowel words and a Max Onset preference for Long Vowel words (coinciding with the syllable in each case). Again, this suggests that L1 orthographic experience has an impact on L2 reading. It seems that when reading experience centers primarily on the morpheme-based Chinese script, there is little or no systematic structuring of alphabetically represented polysyllabic words.

There was a strong indication in the Chinese data of a higher error rate on the Short Vowel words compared to the Long Vowel words, $F 1(1,40)=4.43, p<.05$; $F 2(1,39)=3.88, p>.05$, which was unexpected. However, it should be noted that the items were designed by a Japanese speaker with Japanese participants in mind and there were three words, which happened to have a short vowel, that the Japanese mostly knew, but the Chinese did not. These were lavender, calorie, and radish. The first two of these are examples of words adopted in Japanese from English, though in fact neither the Chinese error rates nor response times were affected by the Use in Japanese factor, all $F^{\prime}$ s $<1$.

Finally, a comparison of the Japanese and Chinese data suggests that the former were considerably slower but less error-prone than the latter. The error difference could probably be put down to the above-stated fact that the items were designed with the Japanese participants' vocabulary in mind. The difference in average RTs (1152 ms for the Japanese versus $741 \mathrm{~ms}$ for the Chinese), however, might possibly reflect some cultural difference in cautiousness of responding, but it is also conceivable that it simply arises from the difference in equipment used. The Japanese were tested on a laptop computer with a keyboard response while the Chinese were tested on a desktop computer with independent response buttons. ${ }^{1}$

\section{GENERAL DISCUSSION AND CONCLUSIONS}

The research reported here offers insight into the way in which polysyllabic words are orthographically represented in lexical memory not only by native speakers of different reading ability, but also by nonnative speakers from different language backgrounds. Both Experiment 1 and previous recent research by Taft (2001) indicate that proficient English reading is associated with a Max Coda (i.e., BOSS) analysis. The suggestion is that a polysyllabic word is optimally represented in lexical memory in terms of syllablelike subunits where the first of these subunits is as informative as possible. When a word is presented with a physical boundary that coincides with this structure, response times are faster than when the boundary cuts across this structure.

If the lexical representation maximizes the informativeness of the first subunit, one might ask why that subunit does not extend beyond the BOSS. For example, why is the cade of cadet considered less informative than the cad of cadet? Indeed, why does there need to be any analysis at all given that the whole word provides the extreme limit of informativeness? It seems that some sort of internal analysis is required even for monosyllabic words, where a breakdown in terms of onset plus "rime", (which is the vowel plus coda ${ }^{2}$ ) has been demonstrated in English (e.g., Treiman \& Chafetz, 1987; Treiman, Mullennix, Bijeljac-Babic, \& Richmond-Welty, 1995). For example, the word bad is analyzed as $b+a d$, and Taft (1991) even

\footnotetext{
${ }^{1}$ Unfortunately, the particular laptop computer that was used to test the Japanese participants is no longer available to examine this possibility.

${ }^{2}$ The rime has also been called the "body" when referring to the orthographic version, as opposed to the phonological version (e.g., Taft, 1991).
} 
suggests that onsets and rimes are explicitly represented as separate units in lexical memory.

The analysis of polysyllabic words, then, may be seen as being equivalent to breaking the word up into manageably sized monosyllabic "subwords," where the first of these (i.e., the one that is processed first when a word is presented) has the standard onset plus rime structure. So, the cade of cadet not only includes the onset plus rime $c+a d$, but also the next vowel, which should rightly be a part of the subsequent unit et. Thus, cad is a more natural structure within the word cadet than is cade. This is consistent with the previously mentioned finding (Taft, 1987) that a BOSS +1 division does not facilitate responding relative to a BOSS division.

Finally, the question can be raised whether the level of reading performance by the nonnative English speakers would be raised if there were explicit training in Maximal Coda analysis. Indeed, such training might prove useful for poorer native English readers as well. This remains a tantalizing prospect, but all we can say at this stage from the present research is that the less proficient readers, both native and nonnative, are giving a qualitatively different orthographic analysis to polysyllabic English words than are the more proficient readers of English.

\title{
APPENDIX
}

\section{The following are the words presented in all of the experiments.}

\begin{abstract}
Short Vowel items: medal, level, cover, moral, clinic, colour, melon, balance, lavender, category, panic, capital, brother, miracle, radish, travel, merit, planet, tonic, salary, calorie, special, camera, lemon, syrup, video, seven, comedy, talent, credit, navigate, money, memory, vinegar, devil, cemetery, modern, manual, linen, limit.
\end{abstract}

Long Vowel items: tiger, major, spider, robot, radio, curtain, junior, pilot, fibre, sofa, harvest, moment, silence, vibration, garden, lever, navy, private, barber, spiral, service, powder, carpet, hero, doctor, basket, circus, basic, station, minus, daughter, native, lunar, pupil, climate, secret, curious, thousand, danger, loyal.

\section{REFERENCES}

Adams, M. (1990). Beginning to read: Thinking and learning about print. Cambridge, MA: MIT Press.

Bradley, D. C., Sánchez-Casas, R. M., \& García-Albea, J. E. (1993). The status of the syllable in the perception of Spanish and English. Language and Cognitive Processes, 8, 197-233.

Brown, J. I., Fishco, V. V., \& Hanna, G. (1993). Nelson-Denny reading test. Itasca, IL: Riverside.

Costa, A., Caramazza, A., \& Sebastian-Galles, N. (2000). The cognate facilitation effect: Implications for models of lexical access. Journal of Experimental Psychology: Learning, Memory, \& Cognition, 26, 1283-1296.

Cutler, A., Mehler, J., Norris, D. G., \& Segui, J. (1986). The syllable's differing role in the segmentation of French and English. Journal of Memory and Language, 25, 385-400.

de Groot, A. M., \& Nas, G. L. (1991). Lexical representation of cognates and noncognates in compound bilinguals. Journal of Memory and Language, 30, 90-123.

Frost, R. (1998). Towards a strong phonological theory of visual word recognition: True issues and false trails. Psychological Bulletin, 123, 71-99.

Inagaki, K., Hatano, G., \& Otake, T. (2000). The effect of kana literacy acquisition on the speech segmentation unit used by Japanese young children. Journal of Experimental Child Psychology, 75, 7091.

Jared, D., Levy, B. A., \& Rayner, K. (1999). The role of phonology in the activation of word meanings during reading: Evidence from proofreading and eye movements. Journal of Experimental Psychology: General, 128, 219-264.

Jordan, T. C. (1986). Testing the BOSS hypothesis: Evidence for position-insensitive orthographic priming in the lexical decision task. Memory \& Cognition, 14, 523-532. 
Kahn, D. (1976/1980). Syllable-based generalizations in English phonology. New York: Garland.

Leong, C. K., \& Parkinson, M. E. (1992). Sensitivity to orthotactic rules in visual recognition by below average readers. Reading and Writing: An Interdisciplinary Journal, 4, 1-17.

Lewellen, M. J., Goldinger, S. D., Pisoni, D. B., \& Greene, B. G. (1993). Lexical familiarity and processing efficiency: Individual differences in naming, lexical decision, and categorization. Journal of Experimental Psychology: General, 122, 316-330

Lima, S. D., \& Pollatsek, A. (1983). Lexical access via an orthographic code? The Basic Orthographic Syllabic (BOSS) reconsidered. Journal of Verbal Learning and Verbal Behavior, 22, 310-332.

Lukatela, G., Lukatela, K., \& Turvey, M. T. (1993). Further evidence for phonological constraints on visual lexical access: TOWED primes FROG. Perception \& Psychophysics, 53, 461-466.

Otake, T., Hatano, G., Cutler, A., \& Mehler, J. (1993). Mora or syllable? Speech segmentation in Japanese. Journal of Memory and Language, 32, 258-278.

Spencer, A. (1996). Phonology. Oxford, UK: Blackwell.

Spoehr, K. T., \& Smith, E. E. (1973). The role of syllables in perceptual processing. Cognitive Psychology, 5, 71-89.

Taft, M. (1979). Lexical access via an orthographic code: The Basic Orthographic Syllabic Structure (BOSS). Journal of Verbal Learning and Verbal Behavior, 18, 21-39.

Taft, M. (1987). Morphographic processing. The BOSS re-emerges. In M. Coltheart (Ed.), Attention \& performance XII. London: Erlbaum.

Taft, M. (1991). Reading and the mental lexicon. Hove, UK: Erlbaum.

Taft, M. (2001). Processing of orthographic structure by adults of different reading ability. Language \& Speech, in press.

Treiman, R., \& Chafetz, J. (1987). Are there onset- and rime-like units in printed words? In M. Coltheart (Ed.), Attention \& performance XII. London: Erlbaum.

Treiman, R., Mullennix, J., Bijeljac-Babic, R., \& Richmond-Welty, E. D. (1995). The special role of rimes in the description, use, and acquisition of English orthography. Journal of Experimental Psychology: General, 124, 107-136.

Van Orden, G. C. (1987). A ROWS is a ROSE: Spelling, sound, and reading. Memory \& Cognition, 15, 181-198. 